\title{
EVALUATION OF RECOVERY FROM ACUTE LUNG INJURY INDUCED BY INTRATRACHEAL INSTILLATION OF ZINC OXIDE NANOPARTICLES
}

\author{
Yoo, J. ${ }^{1, \dagger}-$ SEO, G.B. ${ }^{1,2, \dagger}-$ Yoon, B.I. ${ }^{3}-$ LIM, Y.M. ${ }^{1}-$ KIM, P. ${ }^{1}-$ KIM, H.M. ${ }^{1,{ }^{*}}-$ KwON, J.T. ${ }^{1, *}$ \\ ${ }^{1}$ Environmental Health Research Department, National Institute of Environmental Research, \\ Incheon 404-708, Republic of Korea \\ ${ }^{2}$ Current addresses: Inhalation Toxicology Center, Jeonbuk Department of Non-Human \\ Primate, Korea Institute of Toxicology, Jeonbuk 580-185, Republic of Korea \\ ${ }^{3}$ College of Veterinary Medicine and Institute of Veterinary Science, Kangwon National \\ University, Chuncheon 200-701, Republic of Korea
}

tThese authors contributed equally to this work.

*Corresponding authors

e-mail:inhtox@gmail.com; phone:+82-32-560-7144; fax:+82-32-568-2038

e-mail: hmikim@korea.kr; phone:+82-32-560-7164; fax:+82-32-568-2038

(Received $13^{\text {th }}$ Jan 2018; accepted $26^{\text {th }}$ Mar 2018)

\begin{abstract}
Zinc oxide nanoparticles (ZnO-NPs) can potentially cause adverse health effects because they are highly soluble and widely used. We evaluated the effect of $\mathrm{ZnO}-\mathrm{NPs}$ in rat lung. $\mathrm{ZnO}$-NPs were administered via intratracheal instillation to Sprague Dawley rats at three different dosages $(1,5$, and 10 $\mathrm{mg} / \mathrm{kg}$ body weight). Macrophage numbers, total cell count, and total protein concentrations in bronchoalveolar lavage fluid (BALF) highly increased at day 1 in a dose-dependent manner relative to those in the control. Macrophage numbers and total protein concentrations were still elevated at day 14 relative to baseline, whereas total cell number continued to increase. These results indicate that inflammation had not fully resolved by day 14 in rat lungs. Furthermore, a significant increase in IL-6 (but not TNF- $\alpha$ ) was observed in 5 and $10 \mathrm{mg} / \mathrm{kg}$ dose groups at day 1 , which was likely caused by a $\mathrm{ZnO}-\mathrm{NP}$-treatment-induced increase in polymorphonuclear leukocytes. Histological examination indicated that multifocal acute inflammation occurred in the $\mathrm{ZnO}-\mathrm{NP}$-treated groups and progressed to chronic inflammation by day 14. A partial recovery of lung injury was observed within 14 days after exposure. In conclusion, the results of this study were consistent with those of previous sub-chronic exposure studies.
\end{abstract}

Keywords: nanomaterials, pulmonary toxicity, safety, lung burden, BALF

\section{Introduction}

Nanotechnology, as defined by the International Standards Organization (ISO), is a technology incorporating materials which must be less than $100 \mathrm{~nm}$ in size in at least one axis. As it is cutting edge technology, many industries have striven to innovate in the nanotechnology field in order to overcome physical limitations and improve economic efficiency (Mousavi and Rezaei, 2011, Wetzel et al., 2003). Therefore, nanotechnology has been widely applied in medicines, electronics, and fabrics, and has rapidly spread in consumer products, including cosmetics and personal care goods (McKiernan et al., 2013, Sawhney et al., 2008, Kaur and Agrawal, 2007). Given this, the safety of nanoparticle products must been properly assessed (Nohynek et al., 2010). Metal nanoparticles such as silver, titanium, zinc, and aluminum are widely used. For 
example, zinc nanoparticles (Zn-NPs) and titanium nanoparticles (Ti-NPs) are currently used in sunscreen cosmetics for the prevention of ultraviolet (UV) radiation-induced dermal diseases, including carcinoma and burns (Monteiro-Riviere et al., 2011, Smijs and Pavel, 2011, Nohynek and Dufour, 2012). However, previous studies have shown that metal nanoparticles induced DNA damage and oxidative stress in keratinocytes (Shukla et al., 2011), hepatoma cells (Kim et al., 2009) and lung epithelial cells (Limbach et al., 2007).

Zinc is an essential mineral with important physiological roles in the human body, and many diseases such as diarrhea (Hambidge, 2000), anorexia (Hambidge et al., 1972), and pneumonia (Bhutta et al., 1999) have been associated with zinc deficiency. It has been reported that zinc oxide nanoparticles (ZnO-NPs) are distinct from other metal oxide NPs as they have high solubility (Zhang et al., 2012). The increased production and use of ZnO-NPs enhances the probability of exposure, causing elevated concerns regarding their potential for unintended adverse health effects. Due to their extremely small size, NPs have a very high probability of cellular uptake and interactions with biological molecules and tissues. Indeed, exposure to NPs is not only providing advantageous opportunities, but also potential risks (Zhang et al., 2014).

Therefore, it is imperative to characterize the environmental health and safety aspects of exposure to $\mathrm{ZnO}-\mathrm{NPs}$. However, research investigating the toxicity of $\mathrm{ZnO}-\mathrm{NPs}$ is far behind nanotechnology advances. In vivo results indicate $\mathrm{ZnO}-\mathrm{NP}$ exposure via inhalation poses the most important hazard. However, risk assessments, such as exposure assessments and dose-response relationships of $\mathrm{ZnO}-\mathrm{NP}$ exposure, are relatively scarce. In a previous study, a single intratracheal instillation of rats with 50-70 $\mathrm{nm} \mathrm{ZnO}-\mathrm{NPs}$ and $1000 \mathrm{~nm} \mathrm{ZnO} \mathrm{microparticles} \mathrm{(1} \mathrm{and} 5 \mathrm{mg} / \mathrm{kg}$ Body Weight (BW) respectively) resulted in potent inflammation (Sayes et al., 2007).

Although studies on $\mathrm{Zn}$ nanoparticles have been conducted for several decades (Fosmire, 1990, Xia et al., 2008, Buerki-Thurnherr et al., 2013), information about the effects of ZnO-NPs exposure in the rat lung and its recovery have not been reported in detail. Therefore, the objective of this study was to evaluate the recovery at 14 days from acute lung injury induced by intratracheal instillation of ZnO-NPs in 3 different doses $(1,5$, and $10 \mathrm{mg} / \mathrm{kg} \mathrm{BW})$. We performed intratracheal instillations of $\mathrm{ZnO}-\mathrm{NPs}$ in Sprague-Dawley rats, and the rats were autopsied at 1 or 14 days after installation. Inflammation responses, $\mathrm{Zn}$ burden, and histopathological observations were examined in the collected rat lungs. This study was carried out to examine recovery after intratracheal instillation of $\mathrm{ZnO}-\mathrm{NPs}$ in the rat lung.

\section{Materials and Methods}

\section{Preparation of Zn-NPs}

$\mathrm{ZnO}-\mathrm{NPs}$ used in this study were purchased from Sigma-Aldrich (Sigma-Aldrich, St Louis, MO, USA). ZnO-NPs were dispersed in sterile saline and prepared via $10 \mathrm{~min}$ sonication before starting the experiment. Particle size was measured by transmission electron microscopy (TEM). To investigate the state of dispersion of $\mathrm{ZnO}-\mathrm{NPs}$ when placed into saline as vehicles, samples were analyzed by Dynamic light scattering (DLS). 


\section{Animals and Animal Experimental Design}

Pathogen-free male Sprague-Dawley (SD) rats aged 7 weeks were purchased from Orient Bio Inc (Seongnam, Korea). Animals were acclimatized for at least 1 week prior to starting the study. Rats were randomized into 4 groups ( $n=10$ individuals per group) with a vehicle control group (treated with sterile saline). The doses for intratracheal instillation were selected based on a previous study by Warheit et al (Warheit et al., 2009). The treatment procedures for each group were as follows: animals were exposed to 1 (low exposure group), 5 (middle exposure group), or $10 \mathrm{mg} / \mathrm{kg}$ body weight (high exposure group) doses of $\mathrm{ZnO}-\mathrm{NPs}$ by intratracheal instillation. The control group was exposed to saline. Rats were sacrificed at 1 or 14 days after instillation. All animal experiments were performed according to the Guidelines for Care and Use of the National Institute of Environmental Research.

\section{Acute Pulmonary Analysis}

To investigate acute lung injury, bronchoalveolar lavage fluid (BALF) was obtained by lavaging the lungs five separate times with $3 \mathrm{ml}$ of calcium- and magnesium-free phosphate buffer solution (PBS, $\mathrm{pH}$ 7.4) with the rat deeply anesthetized by isoflurane. The samples were centrifuged at 1,500 rpm for $10 \mathrm{~min}$. The cell-free supernatant of the first lavage was kept separate from other samples for biochemical analysis. The recovered cells from all lavages were resuspended in PBS. The total number of cells (TC) in the BALF were counted with a Vi-Cell ${ }^{\circledR}$ XR analyzer (Beckman Coulter, Brea, CA, USA), and cell differential tests were performed using cytospin preparations (Shandon, Pittsburgh, PA, USA) stained with Diff-Quick staining solution (Fisher Scientific, Swedesboro, NJ, USA). BALF cells (300/rat) were differentially counted as polymorphonuclear leukocytes (PMN) using light microscopy. The total protein (TP) in the BALF supernatant was quantified using a BCA protein assay kit (iNtRON Biotechnology, Seoul, Korea), and the activity of lactate acid dehydrogenase (LDH) in the BALF was measured by using a QuantiChrom Lactate Dehydrogenase Kit (BioAssay Systems, Hayward, CA, USA). The levels of tumor necrosis factor-alpha (TNF- $\alpha$ ) and interleukin-6 (IL-6) in the BALF were estimated by commercially available enzyme linked immunosorbent assay (ELISA) kits (R\&D Systems, Minneapolis, MN, USA), which were performed based on the manufacturer's instructions.

\section{Zinc Burden in Lungs}

Lungs were collected under anesthesia and frozen at $-20^{\circ} \mathrm{C}$ overnight. Then, the samples were weighed, and the zinc burdens in the lungs were quantified with inductively coupled plasma mass spectrometry (ICP-MS, Varian 820-MS, Australia) after microwave-assisted digestion of the samples with $\mathrm{HNO}_{3}$ using a microwave digestion system.

\section{Histopathological Examination}

For histopathological analysis, lungs were collected and fixed in $10 \%$ neutral buffered formalin. Then, the tissues were embedded in paraffin, sectioned (3-5 $\mu \mathrm{m}$ in thickness), and stained with hematoxilin and eosin (H\&E). Stained sections were examined by two toxicological pathologists. If there was a discrepancy in diagnosis 
between the pathologists, the final consensus would be made by discussing the disagreements under dual microscopy (Olympus Co., Tokyo, Japan).

\section{Statistical Analysis}

Analysis of variance (ANOVA) tests and Student's t-tests (GraphPad, San Diego, CA, USA) were used to compare test groups with the control group.

\section{Results and Discussion}

\section{Characterization of $\mathrm{ZnO}$-NPs}

The average primary sizes of $\mathrm{ZnO}$-NPs were measured by TEM, demonstrating a variety of nanoparticle shapes approximately $200 \mathrm{~nm}$ in size, including aggregations (Fig. 1A). DLS analysis showed that ZnO-NPs were agglomerated, and the dispersion of $\mathrm{ZnO}-\mathrm{NPs}$ in saline was observed over a range of 100 to $500 \mathrm{~nm}$ in a dose-dependent manner (Fig. 1B). In the present study, the DLS results were broader in range than the TEM observations regarding primary particle size. This could be explained by the results of a previous study, which showed higher surface absorbed protein concentrations when zinc oxide was diluted in water rather than in PBS (Wells et al., 2012). The above findings illustrate that when surface-absorbed protein concentrations increase, $\mathrm{ZnO}-\mathrm{NPs}$ preferentially form agglomerations. This likely indicates why particle sizes measured using DLS were increased compared to TEM.
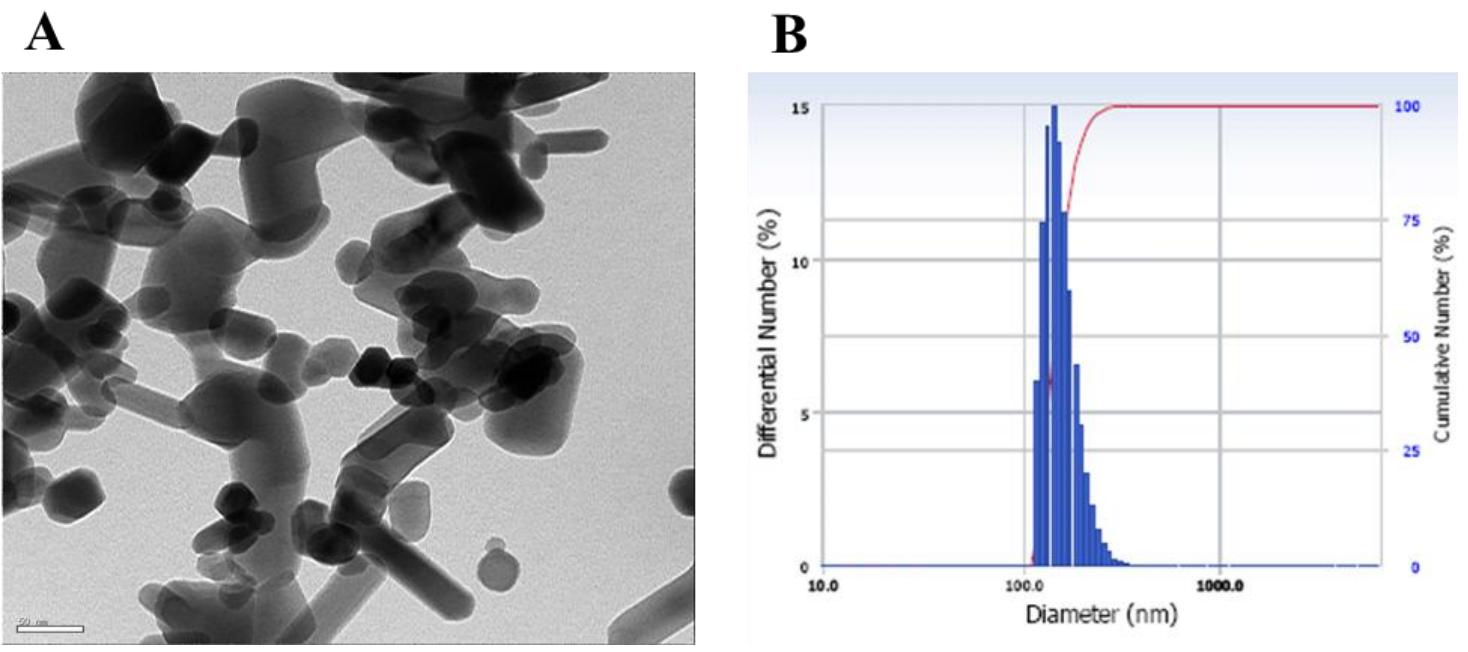

Figure 1. Characterization of exposure conditions. (A) TEM image of Zn-NPs. Scale bar: $50 \mathrm{~nm}$. (B) DLS analysis of Zn-NPs in saline.

\section{Body and Lung Weight}

The body weights of the rats were measured from the $\mathrm{ZnO}-\mathrm{NP}$ exposure day until 14 days after exposure. Body weights increased steadily after treatment in all groups, and no statistical differences between the treatment groups and the control group were observed (Fig. 2A). The relative lung weights of the rats were also measured to identify 
the effect of $\mathrm{ZnO}-\mathrm{NPs}$, and no significant differences were found between treatment groups or between days after exposure (Fig. 2B).

A

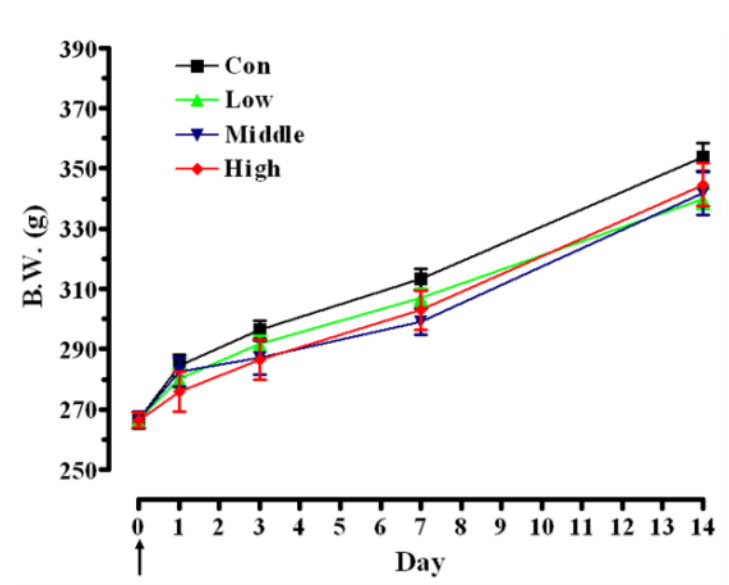

B

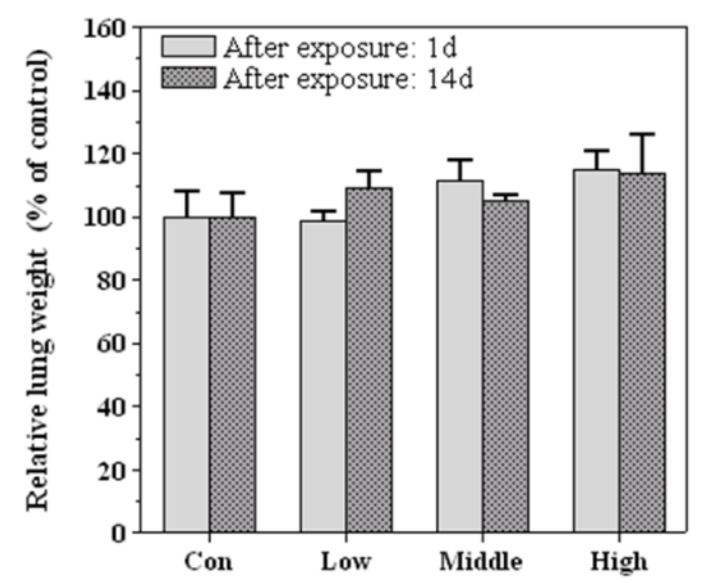

Figure 2. Effect of ZnO-NPs on body and relative lung weights in rats. (A) Body weight change.

(B) Relative lung weight. Data was presented as mean \pm S.E.M.

\section{ZnO-NP Exposure Effects on BALF Cytology}

Cell morphology changes were observed in a dose-dependent manner when intratracheal instillation of ZnO-NPs was performed in rats (Fig. 3A). 1 day after ZnONPs instillation, BALF macrophage presence was increased in a dose-dependent manner. This increase persisted until day 14, although the number of macrophages present at day 14 was lower than that of day 1, suggesting that $\mathrm{ZnO}-\mathrm{NP}$ effects still exist after 2 weeks of non-exposure. Likewise, the total number of cells in BALF increased in a dose-dependent manner after $\mathrm{ZnO}-\mathrm{NP}$ instillation, and persisted even at day 14 after treatment. Indeed, total cells at day 14 were even higher than at day 1 (Fig. 3B). PMNs also increased at day 1 after $\mathrm{ZnO}-\mathrm{NP}$ instillation in a dose-dependent manner, but no difference was detected by day 14 (Fig. 3C). By comparing the ZnO-NP-exposed groups with the control group results in both day 1 and day 14 rats, we can say that recovery after 14 days did occur. In a previous report, rats were exposed to 1 or $5 \mathrm{mg} / \mathrm{kg}$ of $\mathrm{ZnO}$ particles, and lung samples were collected after 1 day, 1 week, 1 month, and 3 months after intratracheal instillation (Sayes et al., 2007). We were able to confirm the increase reported by Sayes et al. in total cell numbers at the dose of $5 \mathrm{mg} / \mathrm{kg}$ at 1 day after instillation. In our study, an additional dosage of instillation was held for $10 \mathrm{mg} / \mathrm{kg}$. In this dosage treated group, the cell number remained increased even after 14 days of recovery. Regarding the proportion of PMNs in total BALF cells, an increase was observed at 1 day after instillation at a dose of $5 \mathrm{mg} / \mathrm{kg}$, but a return to baseline was observed after 14 days. However, an increase in the proportion of PMNs has been reported to be induced by the same dosage at 1 week after instillation (Sayes et al., 2007). Therefore, by combining the previous study and the present report, we were able to identify that intratracheal instillation at a dose of $5 \mathrm{mg} / \mathrm{kg}$ was performed in rats, the proportion of PMNs recovered between 1 and 2 weeks after treatment. 
A
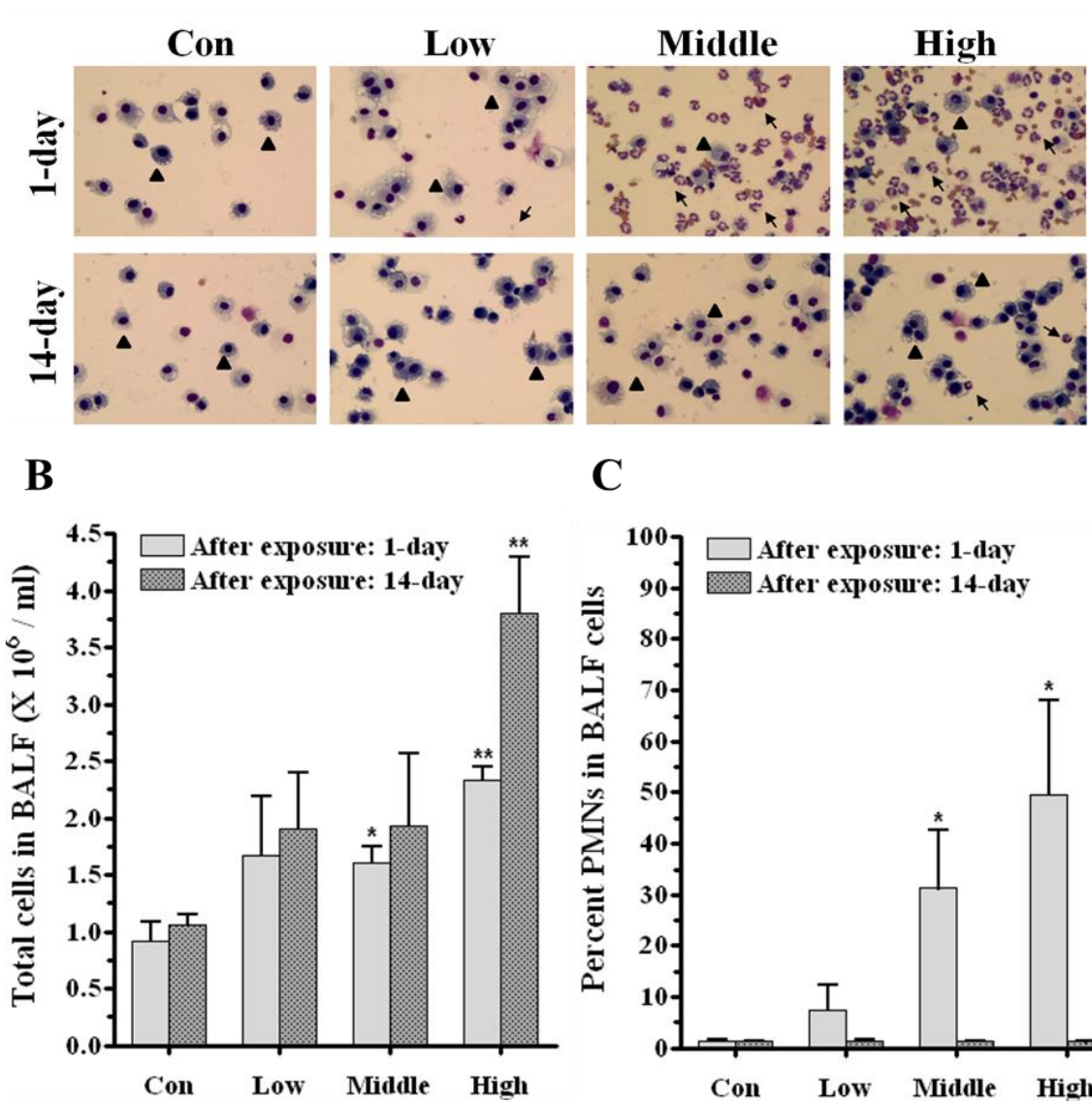

C

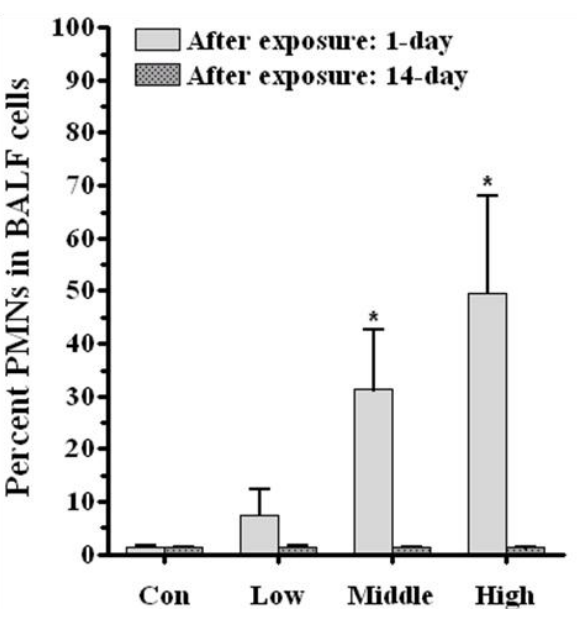

Figure 3. Bronchoalveolar lavage fluid (BALF) cell analysis after instillation of ZnO-NPs. (A) Morphology of BALF cells. (B) Total cell counts. (C) Percent of PMNs in total BALF cells. Data was presented as mean \pm S.E.M. $*=P<0.05$ and $* *=P<0.01$ vs. control.

\section{Effect of ZnO-NPs on BALF Biochemical Parameters}

BALF was collected and analyzed to assess pulmonary inflammation at days 1 and 14 after exposure to $\mathrm{ZnO}-\mathrm{NPs}$. The total protein concentration in BALF increased after treatment in a dose-dependent manner (Fig. 4A). The magnitude of increase was higher on day 1 than day 14, although a slight increase was still present at day 14. This result indicates that inflammation was not fully resolved by 14 days after treatment in rat lung cells.

$\mathrm{LDH}$ is a cytoplasmic enzyme which is present in essentially all major organ systems. $\mathrm{LDH}$ levels in BALF were measured in the control and treatment groups, and no differences were observed, except in the $10 \mathrm{mg} / \mathrm{kg}$ dose treatment group at day 1 after instillation (Fig. 4B). Increases in extracellular $\mathrm{LDH}$ concentrations, which may be caused by cell lysis or cell membrane damage, is used to detect cell damage or cell death (Lott et al., 1986, Click, 1969). Therefore, analysis of BALF LDH concentrations is a potentially useful tool for evaluating lung tissue damage. The increase in LDH caused by high dose $(10 \mathrm{mg} / \mathrm{kg}) \mathrm{ZnO}-\mathrm{NP}$ intratracheal instillation observed after day 1 indicated significant cytotoxicity. However, after 14 days, the LDH level had decreased to that detected in the control group. In a previous report, LDH levels were also found to be recovered at 1 week after $\mathrm{ZnO}-\mathrm{NP}$ exposure at the doses of 1 and $5 \mathrm{mg} / \mathrm{kg}$ (Fukui et al, 2015). In our study, this phenomenon was not only observed in these two dosages, 
but also at a higher dose $(10 \mathrm{mg} / \mathrm{kg})$. Therefore, the recovery of LDH levels appears to occur between day 1 and day 14 in rat lungs.

A

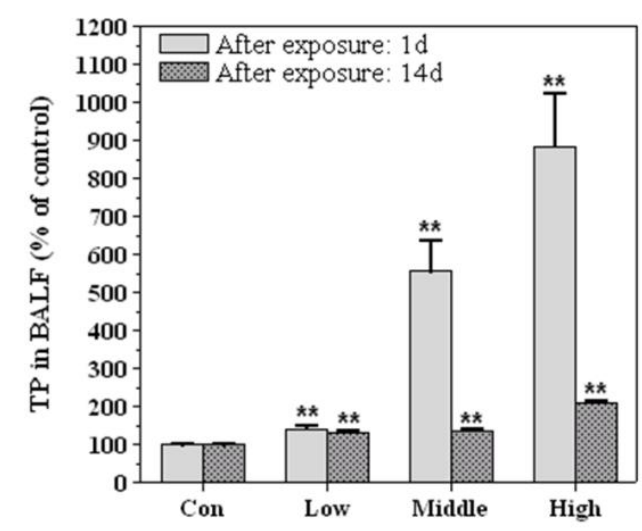

B

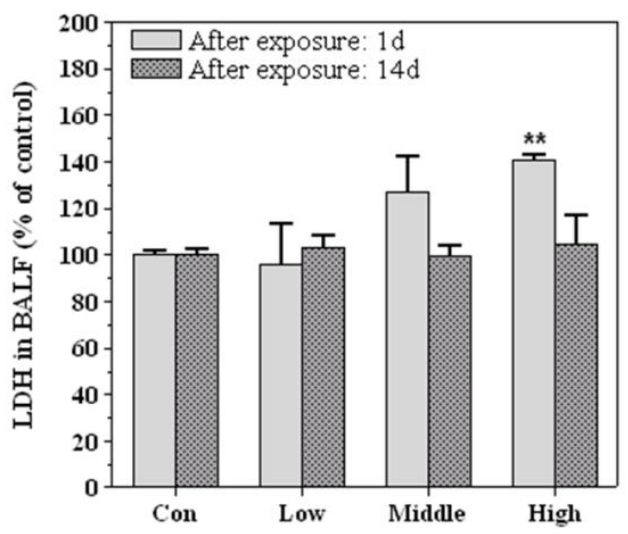

Figure 4. Analysis of biochemical markers in BALF. (A) Change of total protein concentration in BALF. (B) Level of lactate dehydrogenase ( $L D H)$ in BALF. Data was presented as mean \pm S.E.M. $*=P<0.05$ and $* *=P<0.01$ vs. control.

IL-6 is a second wave cytokine, and it has been reported that serum levels of IL-6 increased in lung cancer patients in relation to the intensity of the acute phase response (Yanagawa et al., 1995). Previous studies showed that TNF- $\alpha$ and IL-6 were produced in the airway or BALF during mycoplasmal infection in pigs, and lung inflammation was observed when the production of these cytokines was increased (Asai et al., 1993, Thacker et al., 2000). Therefore, in this study, the levels of inflammatory cytokines, including IL-6 and TNF- $\alpha$, were determined in BALF to examine the inflammatory response to $\mathrm{ZnO}-\mathrm{NP}$ exposure (Fig. 5). IL-6 levels were increased in middle and high dose treatment groups at day 1 (Fig. 5A). However, IL-6 levels in treated rats were the same as control rats at day 14 after instillation. This result indicates that the rat lung was able to recover IL-6 production during the 14 days after treatment. IL-6 enhances endothelial cell expression of leukocyte adhesion molecules and thereby causes leukocyte accumulation in the lung (Gabay, 2006, Barnes et al., 2011). In a previous study reported by Cicco et al investigated the ability of PMN to secrete IL-6 (Cicco et al., 1990). Thus, the increase of IL-6 in the middle and high-dose treated groups at day 1 may be caused by the increase of PMNs in ZnO-NP-treated animals, as PMNs showed the same trend as IL-6. Although IL-6 is mostly produced by macrophages, PMNs have also been reported as predominant sources of IL-6 in lung inflammation (Zhou et al., 1994). Therefore, we were able to confirm that the increase in PMN seems to be related to the observed increase in inflammatory cytokine levels in the BALF.

TNF- $\alpha$ is a cell signaling protein involved in systemic inflammation, and is one of the cytokines that make up the acute phase reaction (Koj, 1996). It is well known that the dysregulation of TNF production is implicated in various diseases, such as Alzheimer's disease (Swardfager et al., 2010), and inflammatory bowel disease (Brynskov et al., 1994). Therefore, we measured the concentration of TNF- $\alpha$ in the BALF. No significant differences between ZnO-NP-treated and control groups were detected at either day 1 or day 14 after exposure (Fig. 5B). A previous study examining IL-6 and TNF- $\alpha$ level in BALF after sub-acute or sub-chronic ZnO-NP exposure had 
noted that lower concentrations of IL-6 and TNF- $\alpha$ were found in the sub-chronic study compared to the sub-acute study (Lampinen et al., 2004). Furthermore, they also found that IL-6 and TNF- $\alpha$ increased immediately after acute exposure (day 1) and progressively decreased with time (day 14), which was similar to the result observed as in the chronic exposure. Therefore, the IL-6 levels found at day 14 in this study showed a similar pattern to the sub-chronic exposure.

A

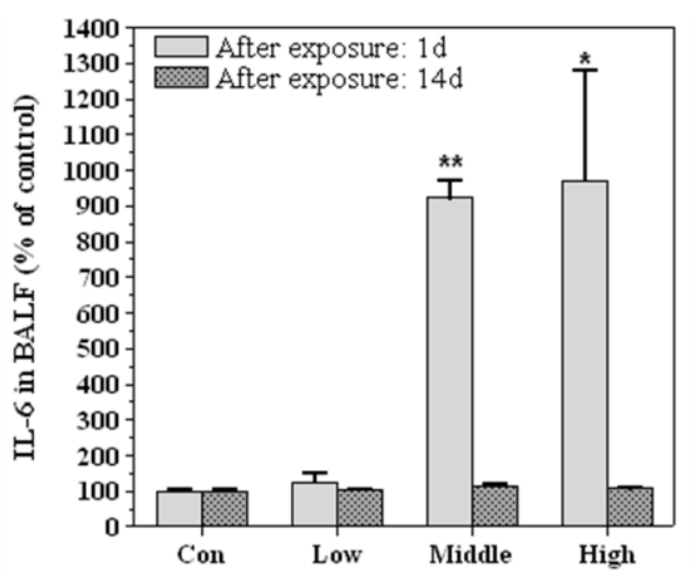

B

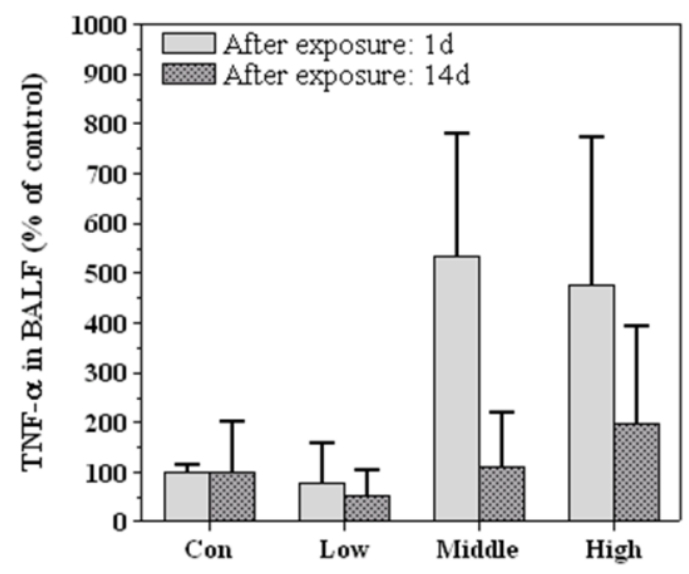

Figure 5. Effect on secretion of cytokine in BALF after exposure of ZnO-NPs. (A) Level of IL-6 in BALF. (B) Concentration of TNF- $\alpha$ in BALF. Data was presented as mean \pm S.E.M. ${ }^{*}=P<$ 0.05 and $* *=P<0.01$ vs. control.

\section{Zinc Burden}

$\mathrm{Zn}$ content in the lung showed different results in relation to the treatment dosage (Fig. 6). Rats sacrificed after day 1 showed a significant increase in all the treatment groups $(\mathrm{P}<0.05$ for low and middle dose treated groups, $\mathrm{P}<0.01$ for the high dose treated group). However, by day 14, a significant increase in lung zinc burden was only observed in rats treated with a $5 \mathrm{mg} / \mathrm{kg}$ dose. These results indicate that $\mathrm{Zn}$ burden was dependent on $\mathrm{ZnO}-\mathrm{NP}$ exposure quantities, and that $\mathrm{Zn}$ burden decreases with time.

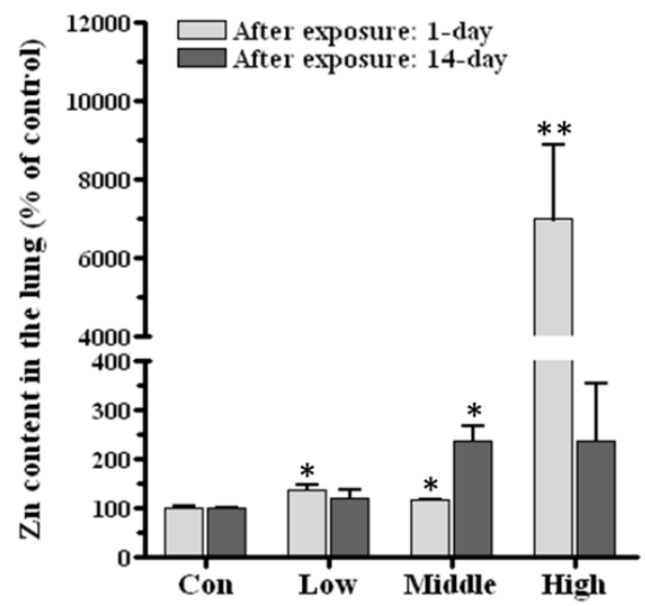

Figure 6. The burden of zinc in the lung after intratracheal instillation of Zn-NPs. Data was presented as mean \pm S.E.M. ${ }^{*}=P<0.05$ and $* *=P<0.01$ vs. control. 


\section{Histopathological Findings}

Histopathological changes were observed in the lungs of rats from the control and treatment groups at day 1 after $\mathrm{ZnO}-\mathrm{NP}$ exposure (Fig. 7). At this timepoint, multifocal acute inflammation was observed near the terminal bronchioles and alveolar ducts in all $\mathrm{ZnO}-\mathrm{NP}$ exposed groups, however no inflammatory lesion was observed in the control group. The inflammation was particularly severe in the high dose group. In the high dose group, pulmonary edema was also often observed. Pervascular infiltration of inflammatory cells was detected in the $\mathrm{ZnO}-\mathrm{NP}$ exposed groups in a dose dependent manner, showing 20\%, 40\%, and 60\% incidence rate in the low dose, middle dose, and high dose exposure groups respectively. Inflammatory cell infiltration near the bronchiole was also observed when inflammatory foci were detected, suggesting that they were related to $\mathrm{ZnO}-\mathrm{NP}$ exposure.

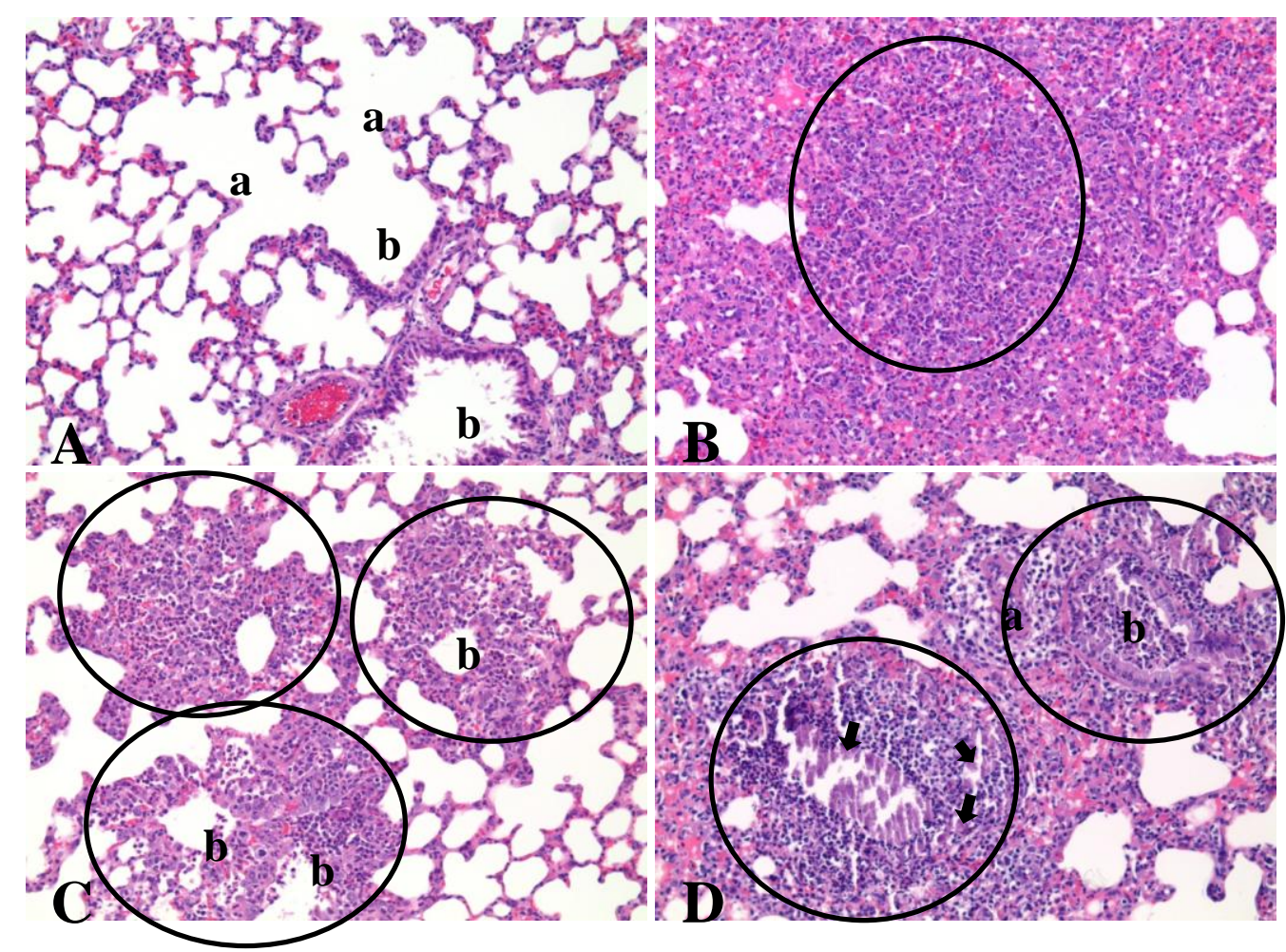

Figure 7. Histopathology of lungs from rats treated with intratracheal ZnO-NPs at day 1 after treatment. Presence of acute bronchopneumonia, as characterized by neutrophil infiltration around the terminal bronchioles with type II alveolar cell hyperplasia, is marked with circles $(B$,

$C$, and $D)$. Dark brown foreign materials were often present in the lesion and bronchiolar lymina (arrows in D). a, arteriole; $b$, terminal bronchioles; $a d$, alveolar ducts. $A=C$ Control; $B$ $=$ Low Dose; $C=$ Middle Dose $; D=$ High Dose. H\&E. Magnification=X200 for all .

Histopathological changes were also observed in the lungs of rats from the $\mathrm{ZnO}-\mathrm{NP}$ treatment groups at day 14 after the exposure (Fig. 8). Chronic histiocytic alveolitis, at the terminal bronchioles and alveolar ducts, was observed at rates of $40 \%, 60 \%$, and $40 \%$ in low, middle, and high dose treatment groups respectively (Fig. 8). The presence of inflammatory cells may be explained as a chronic inflammatory mechanism, where the acute purulent alveolitis observed at day 1 has become chronic due to the passing of 
time. In contrast with the results from day 1, we were not able to observe purulent inflammation or pulmonary edema at the bronchiole at day 14, and this could be considered as a recovery. In low, middle, and high dose of $\mathrm{ZnO}-\mathrm{NP}$ exposure groups, lymphocyte infiltration near the blood vessels were observed as $40 \%, 80 \%$, and $80 \%$ respectively, showing a trend to dosage, although statistically significant difference among the groups were not observed.

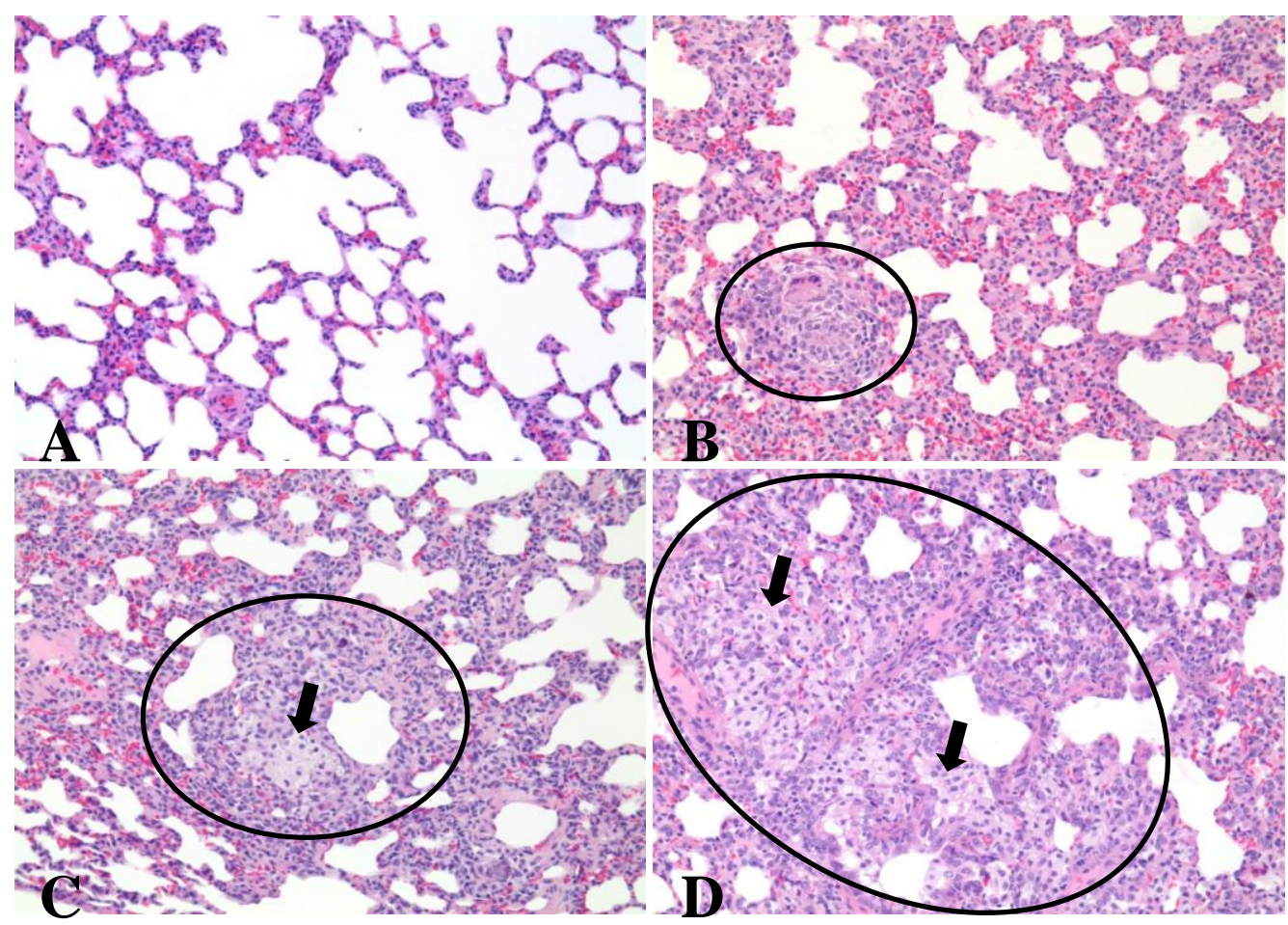

Figure 8. Histopathology of lungs from rats treated with intratracheal ZnO-NPs at day 14 after treatment. Multifocal histiocytic pneumonitis, as characterized by massive infiltration of foamy macrophages(arrows), in the lungs of low, middle and high dose groups are marked with circles $(B, C$ and $D)$. a, arteriole; $b$, terminal bronchioles; $a d$, alveolar ducts. $A=$ Control; $B=$ Low

Dose; $C=$ Middle Dose; $D=$ High Dose. H\&E. Magnification=X200 for all .

In previous studies, histopathological observations revealed serious pulmonary inflammation and alveolar wall thickening in the lungs of treated mice (Chang et al., 2012, Saptarshi et al., 2015). Although the experimental animal used was different, similar results were observed in our $\mathrm{ZnO}-\mathrm{NP}$ exposure experiments. In this study, we observed histopathological differences between day 1 and day 14 after treatment, which suggests some recovery after exposure. Acute bronchopneumonia, as characterized by neutrophil infiltration around the terminal bronchioles with type II alveolar cell hyperplasia, was observed in the $\mathrm{ZnO}-\mathrm{NP}$ treated groups at acute phase (marked with circles in Fig. 7). Multifocal histiocytic pneumonitis was identified at day 14 (Fig. 8), showing that full recovery had not yet occurred by this timepoint, and suggesting that acute inflammation had shifted to chronic infilammation. In the lesions, infiltration of foamy macrophages was frequently detected (arrow in Fig. 8), and macrophage size increased dose-dependently. 


\section{Conclusion}

In the present study, we investigated pulmonary toxicity and histopathology of the lungs of rats exposed to $\mathrm{ZnO}-\mathrm{NPs}$ by intratracheal instillation. The number of macrophages were decreased at day 14 compared to day 1 , although they were still higher than baseline levels, suggesting that the effect of ZnO-NPs still existed at 2 weeks after exposure. The total number of BALF cells increased in a dose-dependent manner after treatment, and continued to increase to day 14 after treatment. However, proportion of PMNs returned to baseline levels between 1 and 2 weeks after treatment with $5 \mathrm{mg} / \mathrm{kg}$ of ZnO-NPs. LDH levels did recover between day 1 and day 14 . Levels of IL-6 increased significantly in rats given 5 or $10 \mathrm{mg} / \mathrm{kg}$ doses at day 1 , while IL-6 levels were stable by day 14 . Based on these results, we can say that recovery was present at day 14 after exposure, which was observed in previous sub-chronic exposure studies. Furthermore, we noted that intratracheal instillation of ZnO-NPs caused multifocal acute purulent inflammation in pulmonary parenchyma. The findings of this study suggest that acute exposure to ZnO-NPs may have deleterious effects in cells, which may lead to tissue damage and possible chronicization of pathological conditions. For further research, examination held after more than 14 days may be required to determine the long-term effects which may be caused by $\mathrm{ZnO}-\mathrm{NPs}$ through ITI.

Acknowledgements. This work was supported by a grant from the National Institute of Environment Research (NIER), funded by the Ministry of Environment (MOE) of the Republic of Korea (NIERRP2013-131).

\section{REFERENCES}

[1] Asai, T., Okada, M., Ono, M., Irisawa, T., Mori, Y., Yokomizo, Y.,Sato, S. (1993): Increased levels of tumor necrosis factor and interleukin 1 in bronchoalveolar lavage fluids from pigs infected with Mycoplasma hyopneumoniae. - Veterinary immunology and immunopathology 38(3-4): 253-260.

[2] Barnes, T. C., Anderson, M. E.,Moots, R. J. (2011): The many faces of interleukin-6: the role of IL-6 in inflammation, vasculopathy, and fibrosis in systemic sclerosis. International journal of rheumatology 2011.

[3] Bhutta, Z., Black, R., Brown, K., Gardner, J. M., Gore, S., Hidayat, A., Khatun, F., Martorell, R., Ninh, N.,Penny, M. (1999): Prevention of diarrhea and pneumonia by zinc supplementation in children in developing countries: pooled analysis of randomized controlled trials. - The Journal of pediatrics 135(6): 689-697.

[4] Brynskov, J., Nielsen, O. H., Ahnfelt-Rønne, I.,Bendtzen, K. (1994): Cytokines (immunoinflammatory hormones) and their natural regulation in inflammatory bowel disease (Crohn's disease and ulcerative colitis): a review. - Digestive Diseases 12(5): 290-304.

[5] Buerki-Thurnherr, T., Xiao, L., Diener, L., Arslan, O., Hirsch, C., Maeder-Althaus, X., Grieder, K., Wampfler, B., Mathur, S.,Wick, P. (2013): In vitro mechanistic study towards a better understanding of $\mathrm{ZnO}$ nanoparticle toxicity. - Nanotoxicology 7(4): 402416.

[6] Chang, Y.-N., Zhang, M., Xia, L., Zhang, J.,Xing, G. (2012): The toxic effects and mechanisms of $\mathrm{CuO}$ and $\mathrm{ZnO}$ nanoparticles. - Materials 5(12): 2850-2871.

[7] Cicco, N. A., Lindemann, A., Vandenbussche, P., Lubbert, M., Gauss, J., Mertelsmann, R.,Herrmann, F. (1990): Inducible production of interleukin-6 by human 
polymorphonuclear neutrophils: role of granulocyte-macrophage colony-stimulating factor and tumor necrosis factor-alpha. - Blood 75(10): 2049-2052.

[8] Click, J. H. (1969): Serum lactate dehydrogenase isoenzyme and total lactate dehydrogenase values in health and disease, and clinical evaluation of these tests by means of discriminant analysis. - American journal of clinical pathology 52(3): 320-328.

[9] Fosmire, G. J. (1990): Zinc toxicity. - The American journal of clinical nutrition 51(2): 225-227.

[10] Fukui, H., Iwahashi, H., Endoh, S., Nishio, K., Yoshida, Y., Hagihara, Y.,Horie, M. (2015): Ascorbic acid attenuates acute pulmonary oxidative stress and inflammation caused by zinc oxide nanoparticles. - Journal of occupational health 57(2): 118-125.

[11] Gabay, C. (2006): Interleukin-6 and chronic inflammation. - Arthritis research \& therapy 8(2): S3.

[12] Hambidge, K. M., Hambidge, C., Jacobs, M.,Baum, J. D. (1972): Low levels of zinc in hair, anorexia, poor growth, and hypogeusia in children. - Pediatr Res 6(12): 868-874.

[13] Hambidge, M. (2000): Human zinc deficiency. - The Journal of nutrition 130(5): 1344S1349S.

[14] Kaur, I. P.,Agrawal, R. (2007): Nanotechnology: a new paradigm in cosmeceuticals. Recent patents on drug delivery \& formulation 1(2): 171-182.

[15] Kim, S., Choi, J. E., Choi, J., Chung, K.-H., Park, K., Yi, J.,Ryu, D.-Y. (2009): Oxidative stress-dependent toxicity of silver nanoparticles in human hepatoma cells. - Toxicology in vitro: an international journal published in association with BIBRA 23(6): 1076.

[16] Koj, A. (1996): Initiation of acute phase response and synthesis of cytokines. Biochimica et Biophysica Acta (BBA)-Molecular Basis of Disease 1317(2): 84-94.

[17] Lampinen, M., Carlson, M., Håkansson, L.,Venge, P. (2004): Cytokine-regulated accumulation of eosinophils in inflammatory disease. - Allergy 59(8): 793-805.

[18] Limbach, L. K., Wick, P., Manser, P., Grass, R. N., Bruinink, A.,Stark, W. J. (2007): Exposure of engineered nanoparticles to human lung epithelial cells: influence of chemical composition and catalytic activity on oxidative stress. - Environmental science \& technology 41(11): 4158-4163.

[19] Lott, J. A., Wolf, P. L., Nemesánszky, E.,Sawhney, A. K. (1986) Clinical enzymology: a case-oriented approachYear Book Medical Pub.

[20] McKiernan, P. J., Cunningham, O., Greene, C. M.,Cryan, S.-A. (2013): Targeting miRNA-based medicines to cystic fibrosis airway epithelial cells using nanotechnology. Int J Nanomedicine 8: 3907-3915.

[21] Monteiro-Riviere, N., Wiench, K., Landsiedel, R., Schulte, S., Inman, A.,Riviere, J. (2011): Safety evaluation of sunscreen formulations containing titanium dioxide and zinc oxide nanoparticles in UVB sunburned skin: an in vitro and in vivo study. Toxicological Sciences: kfr148.

[22] Mousavi, S. R.,Rezaei, M. (2011): Nanotechnology in agriculture and food production. J Appl Environ Biol Sci 1(10): 414-419.

[23] Nohynek, G. J., Antignac, E., Re, T.,Toutain, H. (2010): Safety assessment of personal care products/cosmetics and their ingredients. - Toxicology and applied pharmacology 243(2): 239-259.

[24] Nohynek, G. J.,Dufour, E. K. (2012): Nano-sized cosmetic formulations or solid nanoparticles in sunscreens: a risk to human health? - Archives of toxicology 86(7): 1063-1075.

[25] Saptarshi, S. R., Feltis, B. N., Wright, P. F.,Lopata, A. L. (2015): Investigating the immunomodulatory nature of zinc oxide nanoparticles at sub-cytotoxic levels in vitro and after intranasal instillation in vivo. - Journal of nanobiotechnology 13(1): 6.

[26] Sawhney, A., Condon, B., Singh, K., Pang, S., Li, G.,Hui, D. (2008): Modern applications of nanotechnology in textiles. - Textile Research Journal 78(8): 731-739. 
[27] Sayes, C. M., Reed, K. L.,Warheit, D. B. (2007): Assessing toxicity of fine and nanoparticles: comparing in vitro measurements to in vivo pulmonary toxicity profiles. Toxicological sciences 97(1): 163-180.

[28] Shukla, R. K., Kumar, A., Pandey, A. K., Singh, S. S.,Dhawan, A. (2011): Titanium dioxide nanoparticles induce oxidative stress-mediated apoptosis in human keratinocyte cells. - Journal of biomedical nanotechnology 7(1): 100-101.

[29] Smijs, T.,Pavel, S. Titanium dioxide and zinc oxide nanoparticles in sunscreens: focus on their safety and effectiveness, Nanotechnol. Sci. Appl. 4 (2011) 95-112.

[30] Swardfager, W., Lanctôt, K., Rothenburg, L., Wong, A., Cappell, J.,Herrmann, N. (2010): A meta-analysis of cytokines in Alzheimer's disease. - Biological psychiatry 68(10): 930941.

[31] Thacker, E. L., Thacker, B. J., Kuhn, M., Hawkins, P. A.,Waters, W. R. (2000): Evaluation of local and systemic immune responses induced by intramuscular injection of a Mycoplasma hyopneumoniae bacterin to pigs. - American journal of veterinary research 61(11): 1384-1389.

[32] Warheit, D., Sayes, C.,Reed, K. (2009): Nanoscale and fine zinc oxide particles: can in vitro assays accurately forecast lung hazards following inhalation exposures? Environmental science \& technology 43(20): 7939-7945.

[33] Wells, M. A., Abid, A., Kennedy, I. M.,Barakat, A. I. (2012): Serum proteins prevent aggregation of $\mathrm{Fe} 2 \mathrm{O} 3$ and $\mathrm{ZnO}$ nanoparticles. - Nanotoxicology 6(8): 837-846.

[34] Wetzel, B., Haupert, F.,Zhang, M. Q. (2003): Epoxy nanocomposites with high mechanical and tribological performance. - Composites Science and Technology 63(14): 2055-2067.

[35] Xia, T., Kovochich, M., Liong, M., Mädler, L., Gilbert, B., Shi, H., Yeh, J. I., Zink, J. I.,Nel, A. E. (2008): Comparison of the mechanism of toxicity of zinc oxide and cerium oxide nanoparticles based on dissolution and oxidative stress properties. - ACS nano 2(10): 2121-2134.

[36] Yanagawa, H., Sone, S., Takahashi, Y., Haku, T., Yano, S., Shinohara, T.,Ogura, T. (1995): Serum levels of interleukin 6 in patients with lung cancer. - British journal of cancer 71(5): 1095.

[37] Zhang, H., Ji, Z., Xia, T., Meng, H., Low-Kam, C., Liu, R., Pokhrel, S., Lin, S., Wang, X.,Liao, Y.-P. (2012): Use of metal oxide nanoparticle band gap to develop a predictive paradigm for oxidative stress and acute pulmonary inflammation. - ACS nano 6(5): 4349-4368.

[38] Zhang, Y., Nguyen, K. C., Lefebvre, D. E., Shwed, P. S., Crosthwait, J., Bondy, G. S.,Tayabali, A. F. (2014): Critical experimental parameters related to the cytotoxicity of zinc oxide nanoparticles. - Journal of Nanoparticle Research 16(6): 2440.

[39] Zhou, X., Jordana, M., Kirpalani, H.,Driscoll, K. E. (1994): Cytokine expression by neutrophils and macrophages in vivo: Endotoxin induces tumor necrosis factor-alpha, macrophage inflammatory protein-2, interleukin-1beta, and interleukin-6 but not RANTES or transforming growth factor-beta1 mRNA expression in acute. - American Journal of Respiratory Cell and Molecular Biology 10(2): 148. 